\title{
Proposta de um modelo de avaliação das ações do poder público municipal perante as políticas de gestão de resíduos sólidos urbanos no Brasil: um estudo aplicado ao município de Curitiba
}

\author{
Proposal for an evaluation model for municipal urban solid waste management \\ in Brazil: a study conducted in the city of Curitiba
}

Christian Luiz da Silva ${ }^{[a]}$, Gabriel Massao Fugiii], Alain Hernández Santoyo ${ }^{[b]}$

[a] Universidade Tecnológica Federal do Paraná (UTFPR), Curitiba, PR, Brasil

[b] Universidad Pinar del Rio, Pinar del Rio, Cuba

\section{Resumo}

A gestão de resíduos de sólidos urbanos tornou-se um ponto de inflexão para o desenvolvimento local dos municípios. Há vários modelos sobre planejamento, gestão e tecnologia aplicada aos resíduos sólidos urbanos, mas não há nenhum que se proponha a avaliar o desenvolvimento das políticas municipais dessa área no Brasil. 0 objetivo deste artigo foi propor um modelo de avaliação das ações do poder público municipal ante as políticas de gestão de resíduos sólidos urbanos para o contexto brasileiro. A pesquisa envolveu cinco etapas metodológicas: compreensão das variáveis de análise previstas; pesquisa Delphi para validar as relações entre as variáveis; estruturação de um modelo para avaliação com a relação das variáveis e suas inter-relações; definição dos documentos e instrumentos para aplicação do modelo; aplicação do modelo para o caso de Curitiba. A aplicação do modelo ao plano municipal de Curitiba ressaltou que o município universaliza o serviço e presta os serviços básicos de coleta e disposição final, contudo reutiliza e reaproveita muito pouco dos resíduos. Há um processo de planejamento mais programático e menos estratégico que deveria priorizar o vínculo com a gestão integrada da cadeia.

Palavras-chave: Gestão de resíduos sólidos urbanos. Políticas públicas municipais. Planejamento urbano e regional. Modelo de avaliação. Curitiba.

\section{Abstract}

Urban solid waste management has become an inflection point for the local development of municipalities. There are several models for the planning, management and technology applied to urban solid waste, but there is no model that proposes to evaluate the development of municipal policies in this field in Brazil. The object of this article was to propose an evaluation model for the actions of the municipal authorities regarding their policies of urban solid waste management in the Brazilian context. The study was conducted in five methodological stages: understanding the variables; a Delphi study to validate the relations among the variables; the structuring of an evaluation model with the relation of the variables and their inter-relationships; definition of the documents and instruments for applying the model; application of the model to the case of Curitiba. The application of

CLS é economista, pós-doutor em Administração, e-mail: christiansilva@utfpr.edu.br GMF é biólogo, doutorando em Tecnologia e Sociedade, e-mail: gmfugii@gmail.com AHS é economista, pós-doutor em Tecnologia e Sociedade, e-mail: santoyocuba@gmail.com

urbe. Revista Brasileira de Gestão Urbana (Brazilian Journal of Urban Management), 2017 maio/ago., 9(2), $276-292$ 
the model to the municipal plan of Curitiba emphasized that the city universalizes the service and provides the basic services of collection and final disposal. However, it reclaims and reuses very little of the waste. There is a planning process that is more pragmatic and less strategic, which should prioritize a link with the integrated chain management.

Keywords: Urban solid waste management. Municipal public policies. Urban and regional planning. Evaluation model. Curitiba.

\section{Introdução}

A partir da década de 1990, o número de estudos sobre políticas municipais da gestão de resíduos sólidos e respectivos impactos locais tem crescido (Callan \& Thomas, 1997). Em 2000, alguns estudos se direcionaram sobre como as organizações de reciclagem eram estruturadas, especialmente em países em desenvolvimento (Wilson et al., 2001; Zurbrügg, 2003). Outras pesquisas recentes analisam a otimização da cadeia de reciclagem, políticas públicas e a estruturação de redes (Wan et al., 2014; Saphores \& Nixon, 2014; Santiago \& Dias, 2012; Pires et al., 2011; Othman et al., 2013; Mo et al., 2009; Matsumoto, 2011; Moh \& Manaf, 2014; Lin, 2008; Lakhan, 2014). Adicionalmente, alguns estudos tratam da proposição de modelos de análise das políticas públicas de gestão de resíduos, mas salientam a dificuldade de integralizar diferentes abordagens e temas para um único modelo aplicável em diferentes contextos (Soltani et al., 2015; Guerrero et al., 2013; Plata-Díaz et al., 2014; Bing et al., 2016; Silva et al., 2015).

o Brasil é o quarto maior país em geração de resíduos por ano (em torno de 78 milhões de toneladas por ano), atrás apenas da China, Estados Unidos e Índia. Além disso, enfrenta um importante problema da má disposição dos resíduos. Aproximadamente $42 \%$ do total de resíduos gerados tem um destino final inadequado (ABRELPE, 2014).

Tais indicadores se referem a como se desenvolve a gestão municipal de resíduos sólidos e são importantes para discutir os modelos de avaliação dessa gestão. Estes modelos envolvem diferentes abordagens ou contextos. As abordagens dos estudos podem ser variadas, como a questão da gestão integrada dos agentes envolvidos na cadeia (Santiago \& Dias, 2012); ou a abordagem institucional e a influência das regras formais ou informais na cadeia (Silva \& Biernaski, 2015); ou a avaliação das ações do poder público municipal (Wan et al., 2014); ou a avaliação das ações das empresas e da sociedade civil organizada; ou mesmo a participação e a constituição de redes sociais para políticas e ações de reciclagem (Saphores \& Nixon, 2014; Mo et al., 2009). Por outro lado, há estudos com foco na avaliação da gestão integrada de resíduos segundo um determinado contexto (Zurbrügg, 2003; Wilson et al., 2001; Pires et al., 2011).

Muitos desses estudos sobre proposição de modelos de avaliação partem de uma realidade que não inclui as características do Brasil, como seu contexto institucional e características culturais e de gestão. Envolvem pesquisas em vários continentes, algumas até na América Latina (Guerrero et al., 2013). Mas como analisar o desenvolvimento das políticas municipais de resíduos sólidos? Silva et al. (2015) fazem uma proposição de variáveis-chave para compreender a dinâmica da gestão de resíduos sólidos municipais, mas não propõem um modelo de análise sobre a abordagem da avaliação das ações do poder público municipal. Entretanto, a proposição de um modelo de análise à luz da realidade brasileira é relevante para que compreender a dinâmica das políticas municipais mediante a implantação da Política Nacional de Resíduos Sólidos (PNRS) - (Brasil, 2012). Sobre essa política, há uma série de trabalhos, como o de Nascimento \& Moreira (2010) e o de Silva \& Biernaski (2015), contudo versam sobre a normativa e o marco legal, e não sobre a questão da análise da política.

Dessa forma, considerando que o tema "resíduos sólidos urbanos municipais" é uma Política Nacional, que se trata de um problema relevante para diversos municípios, que há tendência de se agravar pela continuidade de expansão da geração e necessidade de correta disposição e que os municípios empregam e gastam recursos significativos para esse tipo de ação, cabe a seguinte questão: como avaliar as políticas de gestão municipais de resíduos sólidos urbanos no Brasil sob a ótica das ações do poder público local? Com isso, o objetivo do artigo é propor um modelo de avaliação das ações do poder público municipal 
diante das políticas de gestão de resíduos sólidos urbanos para o contexto brasileiro.

A delimitação será a proposição de um modelo segundo as variáveis relevantes identificadas por Silva etal. (2015), por ser um estudo recente e aplicado à realidade brasileira. Além disso, o modelo será aplicado em Curitiba, tendo em vista que a gestão pública desse município desenvolveu práticas e discursos consistentes reconhecidos internacionalmente na década de 1990 (Oliveira, 2001).

0 artigo divide-se em cinco seções, incluindo essa introdução. A próxima seção discorrerá sobre os estudos apontados nessa introdução que nortearam os elementos para proposição do modelo. Em seguida, serão apresentados o método de pesquisa e a proposição do modelo. Por fim, aplicou-se esse modelo em Curitiba e são apresentadas as conclusões.

\section{Modelos de gestão municipal de resíduos sólidos e o contexto brasileiro}

As capitais brasileiras, incluindo o Distrito Federal, concentram $23 \%$ do total da população, sendo $99 \%$ considerada urbana, representando $31 \%$ do produto interno bruto do país (IBGE, 2014). A densidade demográfica das capitais varia de 7.786 habitantes por $\mathrm{km}^{2}$ (Fortaleza) a 50 habitantes por $\mathrm{km}^{2}$ (Boa Vista), enquanto a média brasileira é 23 habitantes por $\mathrm{km}^{2}$, e o PIB per capita varia de 64 mil por habitante (Vitória) a 16 mil por habitante (Alagoas), enquanto a média brasileira é 25 mil por habitante (IBGE, 2014). Tal disparidade exemplificada pelas capitais brasileiras reflete a diversidade e a dificuldade para implantar e implementar políticas nacionais, especialmente no que se refere a resíduos que envolvem aspectos tão complexos quanto a questão cultural, a renda e o território físico-social.

A Lei $\mathrm{n}^{\circ} 12.305$ instituiu a PNRS, que apresenta princípios, objetivos, instrumentos, responsabilidades, definições e diretrizes relativos à gestão integrada e ao gerenciamento ambientalmente adequado dos resíduos sólidos (Brasil, 2010a). Essa lei está regulamentada pelo Decreto $\mathrm{n}^{\circ} 7.404$, de 2010 , que criou como um de seus principais instrumentos o Plano Nacional de Resíduos Sólidos (Brasil, 2010b) e envolve o conceito de gestão integrada de resíduos.

0 conceito de gestão integrada de resíduos combina os fluxos de resíduos com a coleta de resíduos e os métodos de tratamento e disposição (Thomas \& McDougall, 2005). Segundo Puna \& Baptista (2008), o Sistema de Gestão Integrada de Resíduos Sólidos Urbanos atua em duas fases importantes: a primeira é a coleta e a segunda é o tratamento seguido da disposição final. 0 tratamento e a disposição final de resíduo sólido urbano (RSU) englobam a existência de unidades de valorização, tratamento (com recuperação de matéria e/ou energia) e disposição final controlada.

Neste aspecto, vários estudos contribuem para uma melhor compreensão das políticas públicas envolvendo o tema. Callan \& Thomas (1997) pesquisaram sobre o impacto de várias políticas locais e de estado ou governamentais para incrementar os esforços de reciclagem em Massachussets. Conseguiram demonstrar que algumas políticas, como o serviço de coleta e o estabelecimento de preços unitários, têm forte influência no total coletado.

Por outro lado, Lakhan (2014) buscou compreender a relação entre os investimentos municipais realizados para promover a educação sobre o tema e o desempenho na taxa de coleta de reciclados em Ontário, Canadá, e não conseguiu estabelecer essa relação, concluindo que a política necessitava de uma reavaliação. Esses dois estudos demonstram a complexidade do planejamento e gestão de resíduos como políticas públicas ao considerar que as variáveis que influenciam a sua efetividade são diversas e dependem do contexto local. Essa complexidade é contextualizada ao Brasil em Marchi (2015, p. 92). Tal autor discorre sobre a complexidade da gestão integrada da cadeia de resíduos, considerando suas repercussões sociais, governamentais, territoriais e técnicas, bem como seu potencial de impacto no meio ambiente, contextualizados na conjuntura institucional brasileira.

Zurbrügg (2003) investiga o problema na Ásia e reforça o descontrole do tema especialmente em países de baixa renda e em desenvolvimento com forte crescimento demográfico. Conforme essa linha de raciocínio, corroborando com Zurbrügg (2003), Moh \& Manaf (2014) reforçam a complexidade do tema RSU e tratam a necessidade de mudança da política segundo um novo paradigma, ao verificarem que se trata de um dos principais problemas urbanos, considerando as limitações de espaços, saúde e questões ambientais. Eles estudaram a realidade da Malásia e confirmaram que a maioria dos reciclados estava depositada em aterros, gerando perdas pelo 
custo de disposição e de oportunidade pela não utilização. Tal fato também foi apontado pelo estudo do IPEA (2010), que demonstra um desperdício de aproximadamente 8 bilhões de reais ao ano no Brasil, se considerada, conforme a metodologia do estudo, a reciclagem de todos os resíduos potencialmente recicláveis encaminhados para aterros e lixões nas cidades brasileiras por ano.

Moh \& Manaf (2014) tratam isso como um novo paradigma para o qual os governos têm de desenvolver políticas públicas para minimizar e reaproveitar os resíduos. Essa orientação é a premissa da Lei $\mathrm{n}^{0} 12.305 / 2010$, que institui a PNRS, o que institucionaliza esse novo paradigma para políticas urbanas sobre o tema, mas que ainda depende de ser apreendida nos planejamentos e nas gestões municipais, como reforçou Silva \& Biernaski (2015). Para Lin (2008), trata-se de um novo sistema econômico que se retroalimenta em uma economia circular. De acordo com cada realidade, o autor propõe que se estudem modelos e sistemas para otimizar os resultados e embasar a decisão dos gestores, o que realmente demonstra ser uma lacuna para a implementação de políticas desse tipo.

Um dos problemas é a particularidade do tema. Por exemplo, Saphores \& Nixon (2014) estudaram a política de coleta de resíduos reciclados nos Estados Unidos em 2006, segundo uma análise de painel ${ }^{1}$, e concluíram que as variáveis socioeconômicas não são significantes. Wan et al. (2014) mostraram que a intenção de reciclar é influenciada por políticas e comportamentos, mas é extremamente subjetiva e não depende apenas de uma política de educação ambiental, como ressaltou Lakhan (2014), nem mesmo só de fatores socioeconômicos, como propôs Saphores \& Nixon (2014).

Considera-se que um sistema de limpeza urbana efetivo de um município deve ser institucionalizado por meio de um modelo de gestão que contemple a sustentabilidade econômica das operações, garanta a preservação do meio ambiente e também a qualidade de vida da população, que contribua para solucionar problemas sociais gerados por atividades inadequadas de gerenciamento de RSU. Diversos autores, como Martins \& Cândido (2015) e Weiss et al. (2015), vinculam

\footnotetext{
${ }^{1}$ Análise de painel são informações de unidades, indivíduos, empresas ou políticas públicas, por exemplo, que podem ser acompanhadas ao longo do tempo. Referem-se a estudos longitudinais (Greene, 2008).
}

a gestão de RSU a uma das questões prioritárias na discussão de modelos de sustentabilidade urbana.

Assim, é possível analisar que a combinação de diferentes modelos ajustados às necessidades contingenciais de um sistema, presente em um Estado, torna-se um instrumento essencial para que o gerenciamento de RSU ocorra de modo harmonioso entre a sociedade e ecossistemas (Demajorovic, 1995; Zanta \& Ferreira 2003; Silva et al., 2015). Ao passo que tais modelos são ajustados à realidade prática, possibilitam a inovação, o aperfeiçoamento e o desenvolvimento de modelos mais avançados, contemplando as peculiaridades e os obstáculos mais distintos do ambiente no qual será implementado o gerenciamento.

Para Economopoulos (2012), as alternativas de gestão podem basear-se nas tecnologias de tratamentos presentes na Figura 1. Entre as alternativas, destaca-se a separação dos resíduos recicláveis na fonte, sendo reutilizados ou reciclados. Os RSUs misturados podem ser tratados anaeróbica ou aerobicamente, de modo mecânico-biológico, obtendo, assim, materiais recicláveis, combustível (energia) e bioestabilizados orgânicos (fertilizantes/adubo). Os RSUs misturados também podem ser pré-tratados em instalações de secagem biológica, após a recuperação do material reciclável. 0 restante desses tratamentos será resíduo inerte, que não pode ser aproveitado e será direcionado ao aterro sanitário. A energia gerada pode ser exportada sob a forma de eletricidade e/ou calor, para aquecer o local, ou utilizada industrialmente. Por outro lado, cabe destacar que os resíduos com substâncias tóxicas devem ser eliminados em instalações apropriadas.

Othman etal. (2013) apresentam um modelo genérico, porém atual, utilizado nos países desenvolvidos, com a presença de outras formas de tratamento termal, como a gaseificação, a pirólise e a incineração, além de aproveitamento energético, reciclagem e compostagem (Figura 2). Tal modelo é instituído pela seguinte hierarquia e ordem de prioridade: prevenção, preparação para reutilização, reciclagem, outras formas de valoração (como recuperação de energia) e disposição final (Lombardi et al., 2015).

Dessa forma, Silva et al. (2015) estabeleceram uma relação de 36 variáveis mais relevantes para proposição e avaliação de políticas públicas para a gestão de RSU. Tais variáveis foram definidas segundo modelos e estudos existentes, como os de Finnveden et al. (2005), Economopoulos (2012) e Othman et al. (2013), mas 


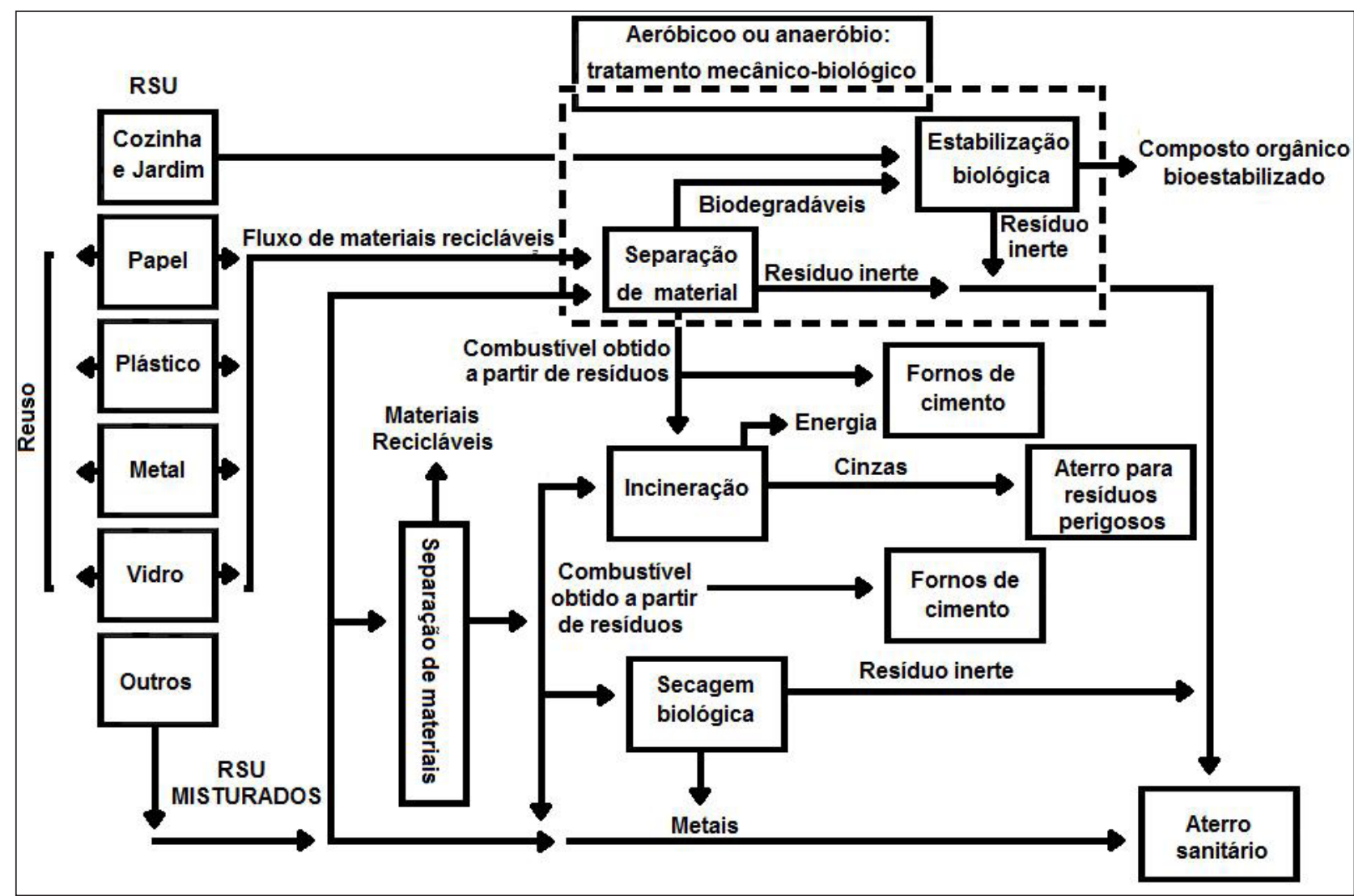

Figura 1 - Fluxo para planejamento e racionalização da gestão de RSU

Fonte: Adaptado de Economopoulos (2012).

considerando a realidade brasileira, com priorização e validação do modelo feita por meio do método Delphi com especialistas brasileiros sobre o tema, tendo sido usado o método de análise multivariada para tratar os dados (Silva et al., 2015).

Nesse modelo, separaram-se as variáveis em três conjuntos: variáveis que podem influenciar ou condicionar as etapas e a gestão de resíduos sólidos; variáveis presentes diretamente nas etapas de gestão dos RSUs; variáveis que fazem parte da forma de gestão. Esse último inclui apenas duas variáveis: cooperativismo e parcerias. As variáveis que influenciam ou condicionam são as mais representativas, tanto em ordem de importância quanto em quantidade. Esse conjunto representa dois terços das variáveis. Por fim, as variáveis presentes diretamente são as dez restantes. As variáveis indicadas e os autores que sustentam sua importância na gestão de RSU estão indicados no Quadro 1, tendo servido como ponto de partida para definir o modelo proposto neste artigo, conforme explicitado na seção metodologia.

\section{Metodologia}

A elaboração de um modelo para avaliar a política de gestão de resíduos municipais envolveu cinco etapas metodológicas:

1. Compreensão das variáveis de análise previstas na pesquisa validada para a realidade brasileira (Silva et al., 2015).

2. Pesquisa por meio de painel de especialistas (Delphi) ${ }^{2}$ para validar as relações entre as variáveis.

3. Estruturação de um modelo para avaliação com a relação das variáveis e suas relações e inter-relações.

${ }^{2} 0$ método Delphi consulta um grupo de especialistas por meio de um questionário aplicado sobre o tema a respeito de eventos futuros e é repassado várias vezes até se obter um consenso entre os envolvidos. É utilizado especialmente na ausência de dados históricos ou quando se deseja estimular a criação de novas ideias ou estabelecer novos parâmetros (Santoyo, 2012). 


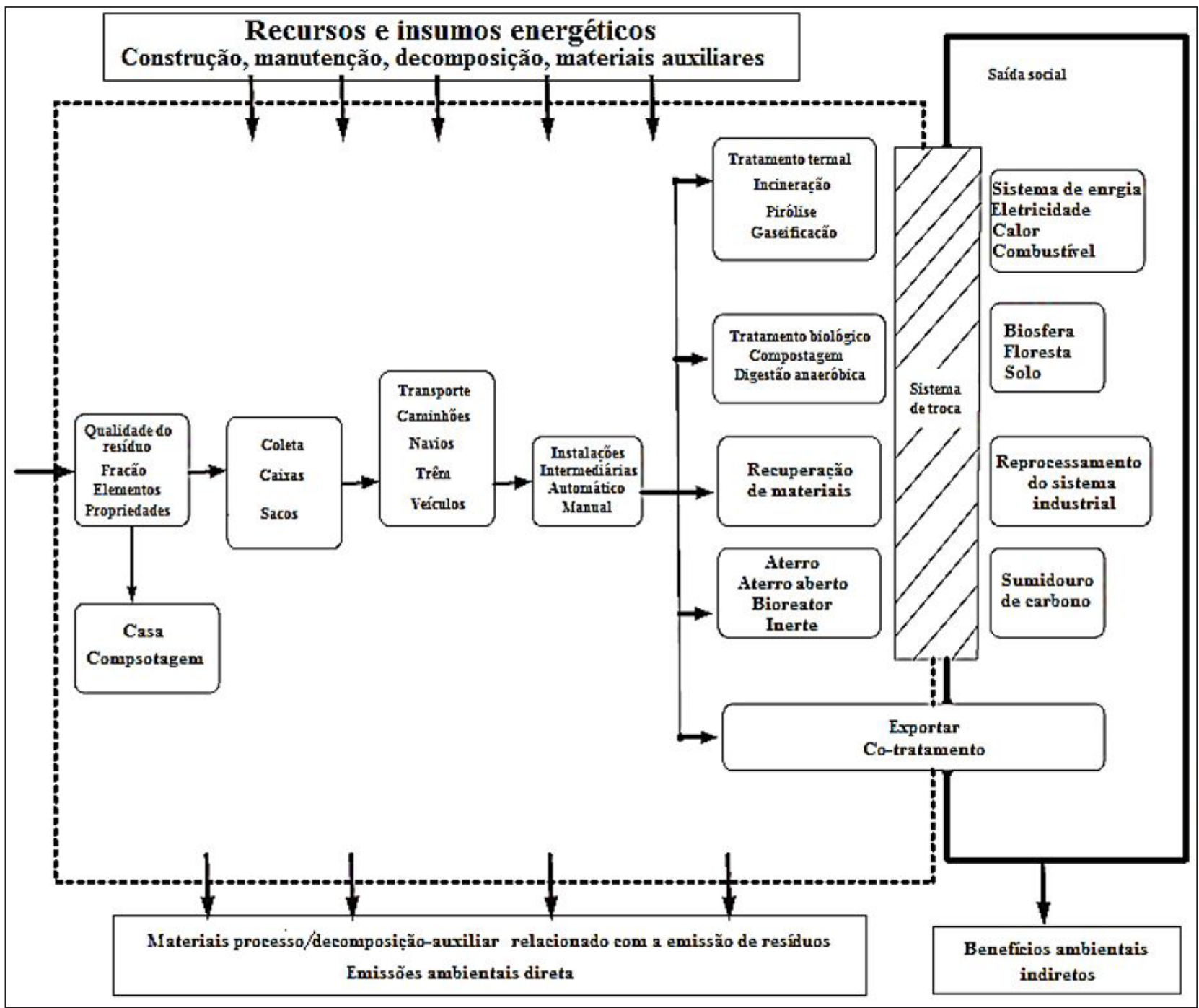

Figura 2 - Sistema genérico de gerenciamento integrado de RSU Fonte: Othman et al. (2013).

4. Definição dos documentos e instrumentos para aplicação do modelo.

5. Aplicação do modelo e análise dos resultados.

A primeira etapa utilizou a técnica de pesquisa documental, referindo-se essencialmente aos trabalhos discutidos na seção anterior. 0 produto dessa etapa foi a produção de um quadro relacionando à variável com sua definição e os autores que consideram tal variável relevante para a gestão municipal de resíduos sólidos urbanos (Quadro 1).

A etapa 2 referiu-se à aplicação de um questionário predominantemente fechado, com uma série de questões envolvendo a gestão de RSU, em que os pesquisadores selecionados por meio do currículo Lattes avaliaram as variáveis previamente selecionadas, por meio de uma escala Likert. As variáveis foram descritas no Quadro 1. 0 levantamento seguiu a metodologia da técnica Delphi, contando com a participação inicial de 120 especialistas, como professores e pesquisadores referentes ao tema.

O Delphi é um dos métodos subjetivos de previsão mais confiáveis, pois retrata a evolução de situações complexas por meio da elaboração de estatística de opiniões de especialistas sobre o assunto (Crespo, 2007). Entre suas principais características, há o anonimato dos participantes que compõem o grupo, garantindo tranquilidade ao defender seus argumentos (Santoyo, 2012).

De acordo com Godet et al. (2000) e Crespo (2007), o método possui três fases. A primeira é a formulação do questionário, seguida pela seleção dos especialistas 
Quadro 1 - Varíáveis relevantes na gestão de RSU

\begin{tabular}{|c|c|c|}
\hline Variável & Descrição & Artigos \\
\hline Acondicionamento & $\begin{array}{l}\text { Artefato adequado para armazenamento (saco de lixo) e local seguro (cesto, } \\
\text { lixeira), longe de animais, evitando contaminação }\end{array}$ & Monteiro et al. (2001); Brasil (2010b) \\
\hline População & $\begin{array}{l}\text { Número de habitantes, sua concentração, renda per capita, grau de instrução, } \\
\text { geraçãa de residuo por habitante, comunidade em torno das instalaç̦óes de } \\
\text { tratamento ou aterro sanitário, participação }\end{array}$ & $\begin{array}{l}\text { US EPA (2002); Zanta \& Ferreira (2003); Dias et al. } \\
\text { (2012); Santiago \& Dias (2012); Polaz \& Teixeira } \\
\text { (2009); Suzuki \& Gomes (2009); Melo et al. (2009); } \\
\text { Lobato \& Lima (2010) }\end{array}$ \\
\hline Educação ambiental & $\begin{array}{l}\text { Ações que foquem a sustentabilidade, iniciativas de ações da população, como a } \\
\text { separaçăo do lixo reciclável do orgañico }\end{array}$ & $\begin{array}{l}\text { Santiago \& Dias (2012); Polaz \& Teixeira (2009); } \\
\text { Melo et al. (2009); Brasil (2010c); Jacobi \& Besen } \\
\text { (2011) }\end{array}$ \\
\hline Coleta & $\begin{array}{l}\text { Seletividade além da frequência da coleta, horário e dia; alternativas e disponibi- } \\
\text { lidade conforme a necessidade da populaçăo (por exemplo, limpeza de quintais e } \\
\text { jardins) }\end{array}$ & $\begin{array}{l}\text { Monteiro et al. (2001); US EPA (2002); Tchobanoglous } \\
\text { \& Kreith (2002); Dias et al. (2012); Santiago \& Dias } \\
\text { (2012); Lobato \& Lima (2010); ABRELPE (2011); } \\
\text { Othman et al. (2013) }\end{array}$ \\
\hline Consumo consciente & $\begin{array}{l}\text { Atrelado à educacãõo ambiental, feito com base em programas/propagandas que } \\
\text { incentivem a consumir o necessário, evitar perdas, exigir soluçōes dos fabricantes, } \\
\text { transportadores comerciantes para tratamento dos resíduos/produtos, praticarem a } \\
\text { reciclagem e reuso, consumo sustentável }\end{array}$ & Santiago \& Dias (2012) \\
\hline Ciclo de vida do produto & $\begin{array}{l}\text { Producucão de artefatos mais duráveis (exemplo: lâmpada) e que ao mesmo tempo } \\
\text { sejam de fácil tratamento e transformaçaćo (reciclagem)/reuso }\end{array}$ & Santiago \& Dias (2012) \\
\hline Ponto de coleta especial & $\begin{array}{l}\text { Locais espećíicos para coleta de determinados resíduos (lâmpadas, pilhas, baterias, } \\
\text { óleo de cozinha) }\end{array}$ & Brasil (2010b) \\
\hline Terceirização & $\begin{array}{l}\text { Descentralizar a terceiros, processos auxiliares (atividade-meio) à atividade principal } \\
\text { (atividade-fim), fiscalização }\end{array}$ & Dias et al. (2012) \\
\hline Infraestrutura urbana & $\begin{array}{l}\text { Condições básicas para implantar um sistema de coleta, ruas bem definidas, } \\
\text { bairros, lixeiras, instalaç̦ôes de tratamento, aterro sanitário, acessibilidade }\end{array}$ & $\begin{array}{l}\text { Santiago \& Dias (2012); Polaz \& Teixeira (2009); } \\
\text { Suzuki \& Gomes (2009) }\end{array}$ \\
\hline Cooperativismo & $\begin{array}{l}\text { Colaboracãão e associaccão de pessoas ou grupos com os mesmos interesses, a fim } \\
\text { de obter vantagens comuns }\end{array}$ & Santiago \& Dias (2012); Lobato \& Lima (2010) \\
\hline Política pública & $\begin{array}{l}\text { Accoes, programas que possam contribuir para o bem- estar da sociedade (resolven- } \\
\text { do problemas) }\end{array}$ & $\begin{array}{l}\text { Zanta \& Ferreira (2003); Santiago \& Dias (2012); } \\
\text { Polaz \& Teixeira (2009); Jacobi \& Besen (2011) }\end{array}$ \\
\hline Capacitação e treinamento & $\begin{array}{l}\text { Accão de trabalhar a parte teórica, prótica e técnica das diversas situaçõos presentes } \\
\text { nas etapas da cadeia de resíduos sólidos }\end{array}$ & $\begin{array}{l}\text { Zanta \& Ferreira (2003); Mesquita (2007); Polaz \& } \\
\text { Teixeira (2009) }\end{array}$ \\
\hline Carrinheiros & Coletores (informais ou formais) de materiais reciláveis & Jacobi \& Besen (2011); Santiago \& Dias (2012) \\
\hline Custo da coleta por habitante & Valor total investido para o funcionamento do sistema & $\begin{array}{l}\text { Monteiro et al. (2001); Zanta \& Ferreira (2003); } \\
\text { Santiago \& Dias (2012); Polaz \& Teixeira (2009) }\end{array}$ \\
\hline Usina de incineração & Local para a queima de resíduos & $\begin{array}{l}\text { US EPA (2002); Schalch et al. (2002); FEAM (2012); } \\
\text { Othman et al. (2013) }\end{array}$ \\
\hline Tratamentos alternativos & Gaseificaç̃̃o, pirólise, plasma e digestão anaeróbica & $\begin{array}{l}\text { Zanta \& Ferreira (2003); Brasil (2010b); FEAM } \\
\text { (2011); FEAM (2012) }\end{array}$ \\
\hline Licença ambiental & $\begin{array}{l}\text { Liberação ambiental pelo responssável legal para a implantaç̣̃o, operaçăo (aterros } \\
\text { sanitários, barracōes etc.) }\end{array}$ & $\begin{array}{l}\text { Santiago \& Dias (2012); Polaz \& Teixeira (2009); } \\
\text { FEAM (2012) }\end{array}$ \\
\hline Compostagem & Ação de transformação do resíduo orgânico em adubo & $\begin{array}{l}\text { Monteiro et al. (2001); US EPA (2002); Thobanoglous } \\
\text { \& Kreith (2002); Schalch et al. (2002); Zanta \& } \\
\text { Ferreira (2003); Santiago \& Dias (2012); Polaz \& } \\
\text { Teixeira (2009); Melo et al. (2009); FEAM (2012); } \\
\text { Othman et al. (2013) }\end{array}$ \\
\hline
\end{tabular}

Fonte: Adaptado de Silva et al. (2015). 
(Conclusão)

\begin{tabular}{|c|c|c|}
\hline Variável & Descrição & Artigos \\
\hline Reciclagem & Ação de transformação do resíduo reciclável em outro ou mesmo produto & $\begin{array}{l}\text { Monteiro et al. (2001); Schalch et al. (2002); US } \\
\text { EPA (2002); Tchobanoglous \& Kreith (2002); Zanta } \\
\text { \& Ferreira (2003); Santiago \& Dias (2012); Brasil } \\
\text { (2010c); ABRELPE (2010, 2011); Jacobi \& Besen } \\
\text { (2011); Othman et al. (2013) }\end{array}$ \\
\hline Manutenção e prevenção & Proteção contra eventuais danos municipais, ambientais e saúde pública & Santiago \& Dias (2012) \\
\hline Universalização dos serviços & Todos os serviços prestados ao alcance de todos & $\begin{array}{l}\text { Mesquita (2007); Brasil (2010a, b); Jacobi \& Besen } \\
\text { (2011) }\end{array}$ \\
\hline Saúde e segurança no trabalho & $\begin{array}{l}\text { Preocupação com o bem-estar e saúde daqueles envolvidos na cadeia de resíduos } \\
\text { sólidos }\end{array}$ & $\begin{array}{l}\text { Monteiro et al. (2001); Ferreira \& Anjos (2001); } \\
\text { Santiago \& Dias (2012) }\end{array}$ \\
\hline Aterro sanitário & $\begin{array}{l}\text { Localização, tamanho, capacidade, vida útil, distância, sua abrangência em atender } \\
\text { a outros municípios (consórcio), normas técnicas e ambientais, monitoramento } \\
\text { ambiental }\end{array}$ & $\begin{array}{l}\text { Monteiro et al. (2001); US EPA (2002); Tchobanoglous } \\
\text { \& Kreith (2002); Zanta \& Ferreira (2003); Santiago } \\
\text { \& Dias (2012); Suzuki \& Gomes (2009); ABRELPE } \\
\text { (2010, 2011); Lobato \& Lima (2010); Othman et al. } \\
\text { (2013) }\end{array}$ \\
\hline Geração de energia & Potencial energético do aterro/tratamento & $\begin{array}{l}\text { US EPA (2002); Mesquita (2007); FEAM (2012); } \\
\text { Othman et al. (2013) }\end{array}$ \\
\hline Fiscalização e informação & $\begin{array}{l}\text { Instrumentos que disponibilizam dados consistentes e confiáveis que servem para } \\
\text { fiscalizar e controlar as ações executadas }\end{array}$ & Brasil $(2010 a, b) ;$ ABRELPE $(2010,2011)$ \\
\hline Geração per capita & Quantidade (massa) gerada por cada habitante & Mesquita (2007) \\
\hline Ponto de coleta voluntária & $\begin{array}{l}\text { Locais específicos para a disposição de resíduos, principalmente áreas de difícil } \\
\text { acesso }\end{array}$ & Brasil (2010b) \\
\hline Logística reversa & Retornos de produtos, embalagens ou materiais aos centros produtivos & Brasil (2010b, c); Tanigaki et al. (2015) \\
\hline Poder público & $\begin{array}{l}\text { Atuação conjunta com os municípios para otimizar o gerenciamento de resíduos } \\
\text { sólidos urbanos }\end{array}$ & Brasil (2010b, c); Mesquita (2007) \\
\hline Comercialização/mercado & $\begin{array}{l}\text { Evitar atravessadores para os materiais recicláveis e composto orgânico, buscando } \\
\text { desenvolver a cadeia produtiva }\end{array}$ & Brasil (2010b); ABRELPE $(2010,2011)$ \\
\hline Planejamento & Estudos estratégicos para aperfeiçoar a gestão de resíduos sólido urbanos & US EPA (2002); Brasil $(2010 a, b, c)$ \\
\hline $\begin{array}{l}\text { Transporte e estação de } \\
\text { transferência }\end{array}$ & $\begin{array}{l}\text { Vários tipos de transporte/pontos de transferência de resíduos (de um caminhão } \\
\text { pequeno para um grande) até o destino final }\end{array}$ & $\begin{array}{l}\text { Monteiro et al. (2001); Tchobanoglous \& Kreith } \\
\text { (2002); Cunha \& Caixeta-Filho (2002); Brasil (2010b); } \\
\text { Othman et al. (2013) }\end{array}$ \\
\hline
\end{tabular}

Fonte: Adaptado de Silva et al. (2015).

e, por último, procedimento prático com exploração de resultados.

Para selecionar os especialistas mais indicados para a pesquisa, utilizou-se a metodologia proposta por Linstone \& Turoff (2002) e Crespo (2007). Tal metodologia baseia-se na autoavaliação dos especialistas, refletindo sobre suas habilidades e fontes que lhes permitam defender seus critérios. A competência de cada especialista foi mensurada por meio de seu coeficiente de competência.

0 valor desse coeficiente corresponde à soma dos critérios obtidos com base nos diferentes graus de influência, considerados pelos especialistas para cada um dos critérios, utilizando um quadro-padrão, no qual valores são atribuídos a cada grau de influência para cada critério (Linstone \& Turoff, 2002). Com esse método, definiram-se os especialistas aptos a participar da aplicação do método Delphi.

Para os especialistas aptos, foi enviado um questionário composto de dois grupos de questões: a primeira referente ao posicionamento do pesquisador quanto à importância de cada variável, em uma escala Likert, com o objetivo de obter informações sobre as principais variáveis e a percepção do entrevistado sobre o planejamento e a prospecção nessa área. A segunda questão era aberta, em que o pesquisado podia complementar a gama de variáveis expostas, caso notasse a ausência de alguma delas.

Para validar os resultados, foi feito um teste de confiabilidade. Para tanto, utilizou-se o coeficiente 
alfa de Cronbach, uma das ferramentas estatísticas mais difundidas e importantes aplicadas a pesquisas (Cortina, 1993; Leontitsis \& Pagge, 2007).

Caso o coeficiente seja maior que 0,7 , é possível afirmar a confiabilidade da escala (Martins, 2006). Para calcular o coeficiente, utilizou-se o programa estatístico Statistical Package for the Social Sciences. $\mathrm{O}$ resultado confirmou a confiabilidade, pois o coeficiente de Cronbach foi 0,922.

A etapa 3 ressaltou a importância que todas as variáveis possuem dentro do sistema. Com base nos modelos existentes e estudados na seção anterior, relacionaram-se as variáveis no modelo teórico representado pela Figura $3^{3}$.

$\mathrm{Na}$ quarta etapa foi aplicado o modelo teórico para avaliar a política de gestão municipal de RSU de Curitiba. Os documentos utilizados foram dados oficiais do município publicados historicamente pelo Sistema Nacional de Informações de Saneamento (SNIS), que possui dados de 2002 a 2014, Plano de Gestão Integrada de Resíduos Sólidos de 2010 e o Plano Municipal de Saneamento de Curitiba de 2013 (Curitiba, 2013). Por fim, aplicou-se um questionário com as variáveis e a respectiva situação segundo as análises dos documentos e dos dados existentes de forma secundária para que fossem validados pelo órgão responsável pelo gerenciamento de resíduos sólidos urbanos da prefeitura.

Esse questionário foi composto de questões abertas e semiabertas, visando ratificar ou não o estágio atual, ou mesmo a presença das variáveis indicadas no modelo proposto (Figura 3). A aplicação do questionário durou 36 dias (de 16 de setembro de 2015 a 22 de outubro de 2015) e dirigiu-se ao órgão da prefeitura municipal responsável pela gestão de resíduos sólidos urbanos do município, que está vinculado à Secretaria Municipal do Meio Ambiente. 0 respondente foi o responsável pela área e complementou-se essa informação com os dados obtidos do plano municipal de saneamento de Curitiba. Não houve divergência de informações, mas complementação e esclarecimento de algumas delas.

A última etapa foi a análise dos resultados, em que se discutiu a situação de cada variável do modelo proposto para o caso estudado.

\footnotetext{
${ }^{3}$ Neste modelo, não se considerou a variável incineração, como proposto por Silva et al. (2015), por não estar alinhada com a PNRS.
}

\section{Estudo aplicado ao município de Curitiba}

Curitiba, capital do Paraná, está distribuída em 75 bairros e possui uma população de 1.751 .907 pessoas (IBGE, 2014). É a cidade-polo do conjunto de 29 municípios que compõem a Região Metropolitana de Curitiba (RMC) (Paraná, 2013).

A cidade possui um plano de gestão integrada de resíduos sólidos, alinhado com a Política Nacional de Resíduos Sólidos (PNRS). Contudo, conforme um estudo detalhado de Silva \& Biernaski (2015), o plano de gestão integrada de resíduos sólidos atende plenamente a 16 incisos da Política Nacional de Resíduos Sólidos, atende parcialmente a dois incisos (VII - Regras de Transporte e IX - Capacitação) e não atende a um inciso (XIII - Custos). Considerando que todos os planos municipais devem contemplar todos os elementos mínimos descritos na PNRS, como se detalha no artigo 19 dessa lei, o Plano de Curitiba deveria ser revisado especialmente nos três incisos anteriormente citados.

O PGIRSU foi revisado e constituiu-se em parte do plano municipal de saneamento de Curitiba (2013), sendo composto de cinco volumes: aspectos gerais, abastecimento de água, esgotamento sanitário, drenagem urbana e resíduos sólidos. Dessa forma, o PGIRSU de 2010 foi substituído por esse volume sobre o tema presente no plano municipal de saneamento, que se alinhou ao artigo 19 da PNRS (Silva, 2016). Esse plano de saneamento foi elaborado com a participação da sociedade civil, do poder público e do setor empresarial. 0 tema Gestão de Resíduos Sólidos foi discutido na Conferência de Meio Ambiente, realizado em 17 de agosto de 2013, com o enfoque em produção, consumo sustentável, impactos ambientais, educação ambiental, geração de emprego, trabalho e renda. A conferência para discutir esse tópico contou com 171 participantes, dos quais 12 pertenciam ao setor empresarial, 74, à sociedade civil e 85 , ao poder público, tendo sido organizada pelo Conselho Municipal de Meio Ambiente (Curitiba, 2013).

Em relação ao tratamento e à destinação final dos resíduos, Curitiba integra o Consórcio Intermunicipal para Gestão de Resíduos Sólidos Urbanos (Conresol), criado com o propósito de organizar e efetivar ações para a gestão do sistema de tratamento e destinação final dos RSUs. A área de abrangência do consórcio corresponde a $9.028,725 \mathrm{~km}^{2}$, totalizando 21 municípios, 


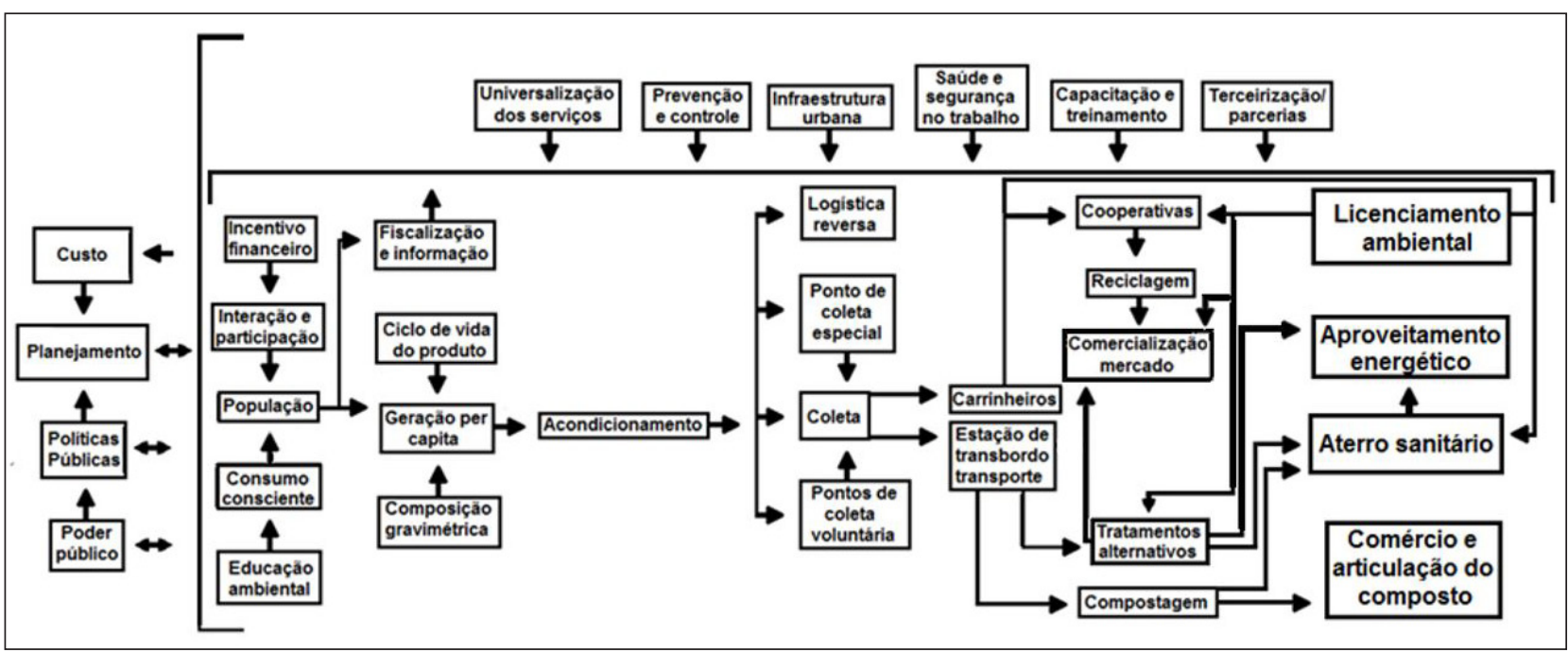

Figura 3 - Modelo teórico de avaliação da política municipal de gestão integrada de RSU Fonte: Elaborada pelos autores.

com uma população de 3.198.598 habitantes (Curitiba, 2013).

Os serviços de coleta de resíduos sólidos urbanos abrangem cem por cento do município. A coleta e o transporte de resíduos úmidos são divididos em coletas indireta e convencional porta a porta. A coleta dos recicláveis é realizada porta a porta, por meio do programa denominado Lixo que não é Lixo, e em pontos de troca, pelo programa chamado Câmbio Verde. A coleta de recicláveis conta, ainda, com o apoio da coleta informal, realizada por catadores de material reciclável (Curitiba, 2013).

Os resíduos recicláveis são destinados a unidades de valorização de recicláveis (UVR), localizadas no município de Campo Magro, administradas pelo Instituto Pró-Cidadania de Curitiba (IPCC), por meio de convênio firmado com o município (Curitiba, 2013).

O IPCC possui diversas unidades de valorização de recicláveis particulares credenciadas, para as quais o excedente de material potencialmente reciclável, oriundo do Lixo que não é Lixo e do Câmbio Verde, é encaminhado. Essas unidades realizam a triagem dos resíduos e comercialização (Curitiba, 2013).

Além disso, os recicláveis podem ser destinados ao Projeto Reciclagem Inclusão Total — Ecocidadão, que é realizado nos Parques de Recepção de Recicláveis, espaços dotados de infraestruturas física, administrativa e gerencial para recepção, classificação e venda do material coletado pelos catadores organizados em sistema de associações ou cooperativas (Curitiba, 2013).

O município possui também coletas de resíduos tóxicos domiciliares. Tais materiais são coletados em dias específicos nos terminais de ônibus, assim como óleos de origens animal e vegetal, os quais são acondicionados em garrafas PET. Outros serviços realizados pela prefeitura são coleta de resíduos vegetais (podas de árvores e limpeza de jardins), resíduos da construção civil e serviços de limpeza. Tais ações são realizadas por empresas contratadas e os resíduos são encaminhados para disposição final em aterros sanitários particulares (Curitiba, 2013).

Com o fim do Aterro da Caximba, o município passou a dispor seus resíduos nos aterros sanitários particulares da Essencis Soluções Ambientais S. A., situada em Curitiba, e da Estre Ambiental S. A., situada no município de Fazenda Rio Grande. A remuneração do serviço de destinação final é feita mensalmente pela quantidade total de resíduos encaminhados ao aterro (Curitiba, 2013).

Atualmente, as variáveis Compostagem, Estação de transbordo, Logística reversa e Geração de energia ou Aproveitamento energético não estão sendo aplicadas ao modelo de gestão de resíduos sólidos de Curitiba, mas são mencionadas nos documentos municipais como ações futuras, o que não acontece com a variável Comércio e articulação do composto gerado. 0 modelo proposto neste artigo (Figura 3) sustenta a necessidade de compreender a dinâmica e 
a inter-relação de diferentes variáveis fundamentais à gestão de resíduos sólidos urbanos alinhada com os objetivos e princípios da PNRS. 0 modelo de gestão de Curitiba incorpora muitas dessas variáveis, como se identificou na pesquisa (Figura 4). Contudo, há elementos importantes com que se preocupar em termos de planejamento e gestão no município.

No que se refere à questão das políticas e à ação do poder público, há um processo institucional bem delineado na gestão, mas que necessita de ajustes pontuais no plano municipal. Há diversos programas instituídos e uma agenda política na gestão municipal sobre o tema. 0 planejamento é efetivo na sua forma programática, mas há carência de visão integrada da gestão de resíduos. Essa carência é a mesma exposta no estudo de Lakhan (2014). Tal fato pode ser observado na ausência de um processo de planejamento da gestão integrada desde a geração até a disposição final.

A questão do custo é uma preocupação porque há tendência de maior financiamento de todo o serviço pelo setor público, como demonstra a Figura 5.0 custo crescente faz aumentar os recursos envolvidos com esse serviço público, os quais concorrerão com recursos orçamentários direcionados a outras funções sociais. Tal questão pode exigir um novo modelo de gestão e de financiamento dos serviços no futuro e merece destaque em termos de planejamento no momento, como ressaltam Moh \& Manaf (2014). Contudo, o custo do serviço por habitante, se comparado ao de outras capitais brasileiras de mesmo porte, é menor (Figura 6).

A gestão municipal sobre o tema tem programas de educação ambiental e há canais e incentivos para interação e participação da sociedade, como audiências e consultas públicas, além do número 156, que é um importante canal de comunicação com a população. Entretanto, não há ação estruturada sobre o consumo consciente, como demonstra o indicador de baixo percentual de resíduos reciclados (Figura 7). Essa situação reforça os resultados de Saphores \& Nixon (2014), assim como os de Wanet al. (2014), que demonstram não ser apenas a educação ambiental o único fator para incrementar a taxa de reciclagem, visto que esta depende também de outros fatores subjetivos. Não se observam esforços de ações do poder municipal de Curitiba com estratégias para estabelecer preços unitários para organizar e estimular a gestão da cadeia de resíduos, como exemplificou o estudo de Callan \& Thomas (1997), que infere algo semelhante em Curitiba.

Apesar de a geração per capita ser baixa, se comparada com a de outras capitais brasileiras do mesmo porte (Figura 8), não há uma preocupação com o ciclo de vida do produto, o que reforça a necessidade de mais efetividade nas ações de consumo consciente e planejamento do processo de gestão integrada. Não há estudos sobre modelos e sistemas para otimizar os resultados e apoiar a decisão dos gestores,

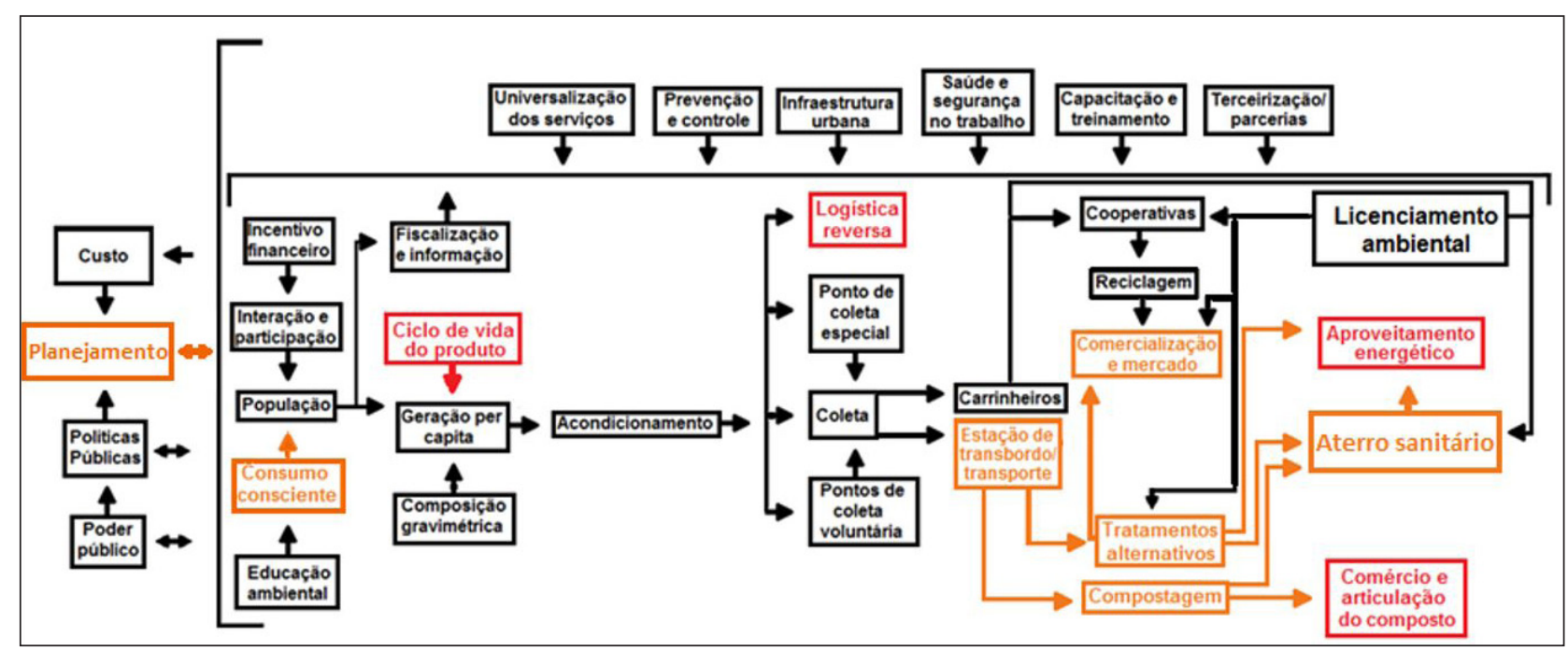

Figura 4 - Modelo de avaliação da políica municipal de gestão integrada de RSU aplicado ao município de Curitiba. Cor preta: alinhado com a PNRS e o modelo; Cor laranja: parcialmente alinhado com a PNRS e o modelo; cor vermelha: não alinhado com a PNRS nem com o modelo Fonte: Elaborada pelos autores. 


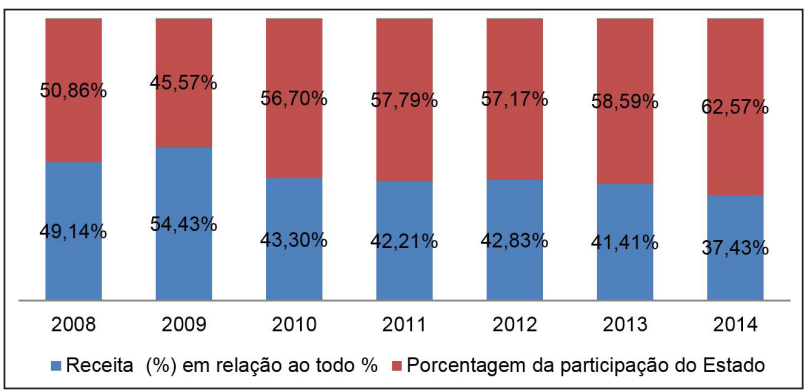

Figura 5 - Fonte de recursos para a gestão de resíduos do município de Curitiba: 2008-2014

Fonte: Sistema Nacional de Informaç̃oes sobre Saneamento (SNIS, 2008, 2009, 2010, 2011, 2012, 2013, 2014).

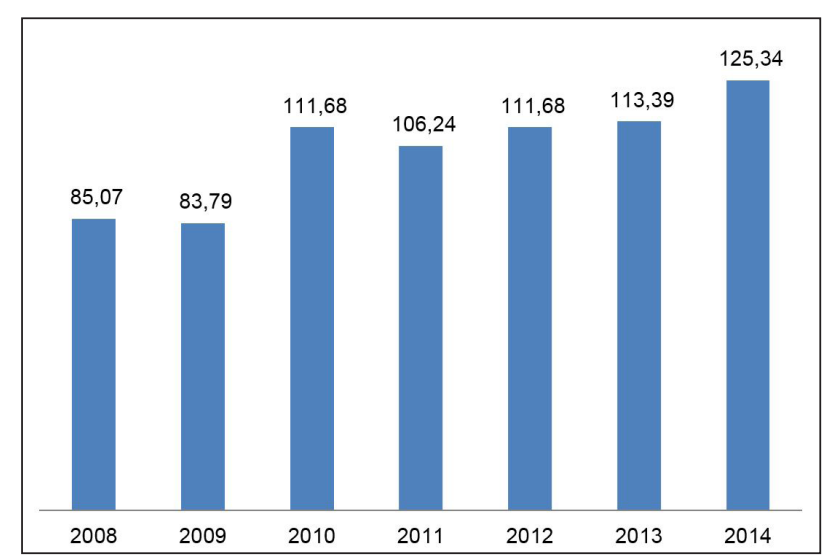

Figura 6 - Custo da limpeza urbana por ano: $R \$$ /ano a preços de 2014 Fonte: Sistema Nacional de Informaç̃oes sobre Saneamento (SNIS, 2008, 2009, 2010, 2011, 2012, 2013, 2014).

como retrata Lin (2008). Sem essa preocupação em termos de planejamento e gestão, cria-se um processo contínuo de lidar a gestão de resíduos como um problema público, sem observar as potencialidades relativas à reutilização, à reciclagem e à redução dos resíduos sólidos.

A gestão da coleta é um ponto forte porque o município dispõe de alternativas para ponto de coleta especial, coleta por meio de caminhões, uma política voltada aos catadores e pontos de coleta voluntária, como já foi mencionado. Entretanto, não há uma ação voltada à logística reversa, o que remonta à falta de compreensão e à ocupação de um tema que geraria mais ganho para toda a cadeia de resíduos. Há, também, a previsão de estações de transbordo, mas isso não se concretizou, o que seria relevante para o destino diferenciado dos resíduos, fosse compostagem,

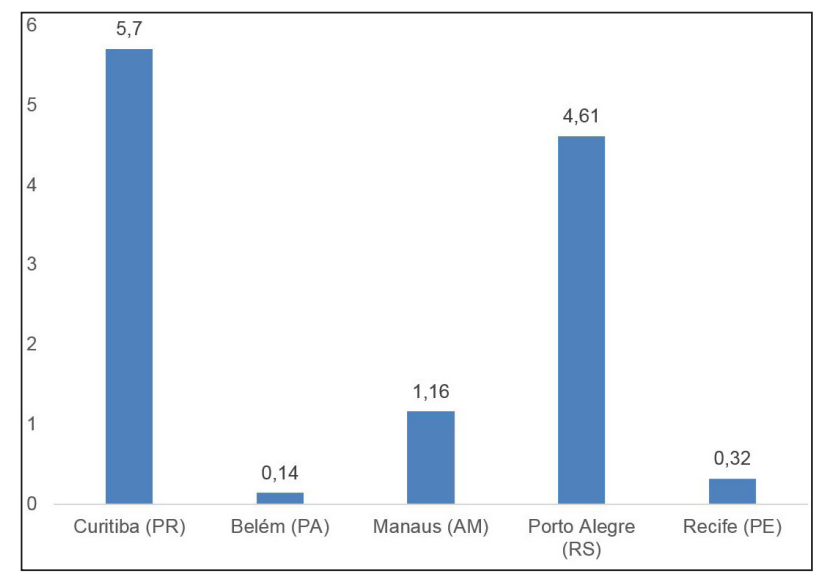

Figura 7 - Percentual do resíduo coletado reciclado de Curitiba, Belém, Manaus, Porto Alegre e Recife (2014)

Fonte: Sistema Nacional de Informações sobre Saneamento (SNIS, 2014).

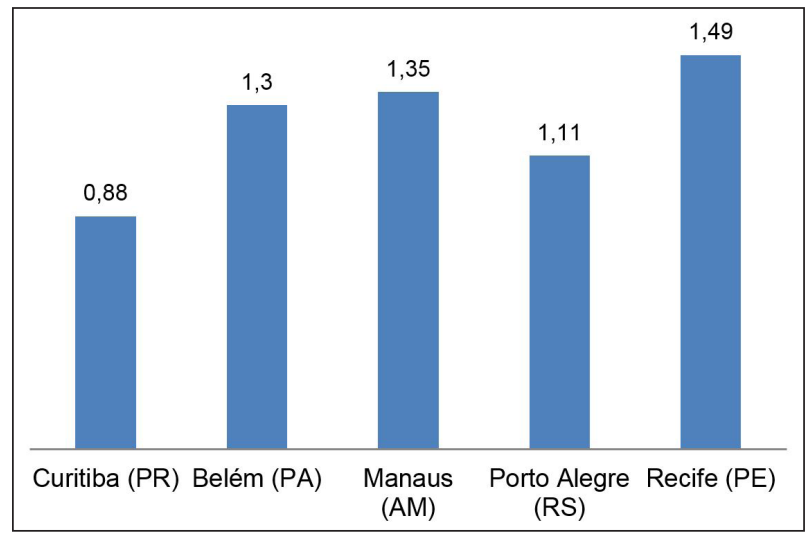

Figura 8 - Geração de resíduos hab./kg/dia em 2014, nos municípos de Curitiba (PR), Belém (PA), Manaus (AM), Porto Alegre (RS) e Recife (PE) Fonte: Sistema Nacional de Informações sobre Saneamento (SNIS, 2014).

tratamentos alternativos, comercialização, mercado ou mesmo a disposição final no aterro. Essa carência se revela também na necessidade de explorar mais as alternativas de reuso e reciclagem, demonstrada pelo baixo índice de reciclagem (Figura 6), por exemplo.

A disposição final é um tema polêmico. Com o fim da vida útil do aterro da Caximba, iniciou-se um projeto de consórcio intermunicipal, que não se concretizou. Há uma situação provisória de compartilhamento de um aterro em Fazenda do Rio Grande, mas o tema ainda não foi solucionado. Tal fato reforça uma maior preocupação com a gestão integrada da cadeia, porque se houver apenas aumento contínuo da geração e baixo reaproveitamento do resíduo gerado, essa questão será um problema crescente e 
produzirá gastos ou perdas públicas. Em meio a isso, houve tentativas de reaproveitamento energético do biogás gerado no aterro, mas tal fato igualmente não se concretizou. Essa situação reforça a necessidade de um planejamento integrado da cadeia de resíduos.

Com o estudo, pode-se verificar que ainda se está distante de um modelo harmonioso de gerenciamento de RSU entre sociedade e ecossistemas, como apontam Demajorovic, (1995), Zanta \& Ferreira (2003) e Silva et al. (2015). A despeito de Curitiba ter reconhecimento pela política de reciclagem na década de 1990, como discute Oliveira (2001), há muito que avançar em um processo de gestão integrada de RSU. Não se trata de uma situação de descontrole, como citado em Zurbrügg (2003), mas de mudança de política segundo um novo paradigma, como ressaltam Moh \& Manaf (2014).

\section{Considerações finais}

A gestão de resíduos sólidos urbanos demanda uma ação integrada entre os diversos atores e variáveis da cadeia, de acordo com as especificidades de cada região e população, devendo ser planejada pelo poder público municipal. Não basta a promulgação da lei que definiu a PNRS para que os princípios e objetivos sejam cumpridos e adequados à realidade dos municípios brasileiros.

A complexidade da gestão de resíduos sólidos urbanos no âmbito municipal envolve uma gestão interdisciplinar sob os aspectos econômicos, ambientais, sociais e institucionais, constituída de pluralidade de atores, com influência de fatores políticos e culturais presentes no cerne do seu desempenho.

Nesse sentido, a questão norteadora desta pesquisa foi responder como avaliar as políticas de gestão municipais de resíduos sólidos urbanos no Brasil sob a ótica das ações do poder público local.

A proposta do modelo de avaliação da gestão integrada de resíduos sólidos consolidou um arranjo de variáveis e interações que permitiu compreender as relações de dependência e a importância relativa de cada variável. Nesse modelo proposto, há variáveis que tangenciam a complexidade de toda a gestão, como a questão institucional (papel e intervenção do Estado), o modelo econômico (reuso e reutilização dos recursos) e, ainda, as questões ambiental (reaproveitamento, coletas especiais e disposição final adequada) e social (geração de renda e emprego).
A aplicação do modelo ao plano municipal de Curitiba ressaltou que o município universaliza o serviço e presta os serviços básicos de coleta e disposição final, contudo reutiliza e reaproveita muito pouco dos resíduos, seguindo a baixa média de outras capitais de porte similar. Por outro lado, há um processo de planejamento mais programático e menos estratégico, com vínculo à gestão integrada da cadeia. Nesse aspecto, não se priorizam a discussão nem as ações sobre consumo consciente, ciclo de vida do produto, logística reversa e aproveitamento energético. Estes poderiam ser meios importantes para um melhor reúso, reutilização ou redução da geração de resíduos. Por outro lado, também não se aprofunda na discussão integrada de estações de transbordo que poderiam organizar esse processo de reúso e reutilização no final da cadeia de resíduos, bem como não explora os tratamentos alternativos nem a compostagem.

Há variáveis e relações não significativas no modelo atual do município, mas para as quais há previsão de incremento contínuo, que pode tornar-se um problema. Destes, destacam-se o custo por habitante e a fonte de financiamento dos serviços públicos. Outro ponto é o aterro sanitário, que apresenta situação transitória e polêmica em torno das alternativas após o encerramento das atividades do aterro da Caximba.

Apesar dos aspectos positivos da execução da política de gestão de RSU pelo poder público de Curitiba, é necessário enfrentar tal problema sob um novo paradigma que integre a cadeia e permita o incremento do reúso e reaproveitamento, bem como a redução dos resíduos. Por fim, a estruturação do modelo de avaliação permitiu compreender a importância das variáveis e suas relações e implicações quando aplicadas ao estudo de caso - assim, pode ser utilizado e replicado em outras regiões para que os resultados possam promover, como neste presente estudo, elementos para propor um planejamento estratégico da gestão integrada de RSUs que promova maior alinhamento do plano municipal com a PNRS e a execução com uma política de redução, reúso e reutilização dos resíduos.

\section{Agradecimentos}

Os autores agradecem ao apoio financeiro da CAPES e do CNPq (Processo 308634/2013-6 e 304515/2016-7) para o desenvolvimento da pesquisa. 


\section{Referências}

Associação Brasileira de Empresas de Limpeza Pública e Resíduos Especiais - ABRELPE. (2010). Panorama dos resíduos sólidos no Brasil 2010. São Paulo. Recuperado em fevereiro de 2017, de http://www.abrelpe.org.br/ Panorama/panorama2010.pdf

Associação Brasileira de Empresas de Limpeza Pública e Resíduos Especiais - ABRELPE. (2011). Panorama dos resíduos sólidos no Brasil 2011. São Paulo. Recuperado em junho de 2012, de http://www.abrelpe.org.br/panorama_ envio.cfm?ano=2011

Associação Brasileira de Empresas de Limpeza Pública e Resíduos Especiais - ABRELPE. (2014). Panorama dos resíduos sólidos no Brasil 2014. São Paulo. Recuperado em fevereiro de 2016, de http://www.abrelpe.org.br/ Panorama/panorama2014.pdf

Bing, X., Bloemhof, J. M., Ramos, T. R. P., Barbosa-Povoa, A. P., Wong, C. Y., \& Van der Vorst, J. G. A. J. (2016). Research challenges in municipal solid waste logistics management. Waste Management, 48(2), 584-592. PMid:26704064. http://dx.doi.org/10.1016/j.wasman.2015.11.025.

Brasil. (2010a, 3 de agosto). Decreto-Lei $n^{\circ}$ 12.305, de 2 de agosto de 2010. Institui a Política Nacional de Resíduos Sólidos; altera a Lei no 9.605, de 12 de fevereiro de 1998; e dá outras providências. Brasília: Diário Oficial da União da União.

Brasil. (2010b, 21 de junho). Decreto $n^{\circ}$ 7.217, de 21 de junho de 2010. Regulamenta a Lei no 11.445, de 5 de janeiro de 2007, que estabelece diretrizes nacionais para o saneamento básico, e dá outras providências. Brasília: Diário Oficial da União da União.

Brasil. (2010c, 23 de dezembro). Decreto $n^{\circ}$ 7.404, de 23 de dezembro de 2010. Regulamenta a Lei no 12.305, de 2 de agosto de 2010, que institui a Política Nacional de Resíduos Sólidos, cria o Comitê Interministerial da Política Nacional de Resíduos Sólidos e o Comitê Orientador para a Implantação dos Sistemas de Logística Reversa, e dá outras providências. Brasília: Diário Oficial da União da União.

Brasil. Ministério do Meio Ambiente. (2012). Plano Nacional de resíduos sólidos. Brasília. Recuperado em 1 junho de 2013, de http://www.sinir.gov.br/ documents/10180/12308/PNRS_Revisao_Decreto_280812. pdf/e183f0e7-5255-4544-b9fd-15fc779a3657
Callan, S. J., \& Thomas, J. M. (1997). The impact of state and local policies on the recycling effort. Eastern Economic Journal, 23(4), 411-423.

Cortina, J. M. (1993). What is coefficient alpha? An examination of theory and applications. The Journal of Applied Psychology, 78(1), 98-104. http://dx.doi. org/10.1037/0021-9010.78.1.98.

Crespo, T. (2007). Respuestas a 16 preguntas sobre el empleo de expertos em la investigación pedagógica (1. ed.). Lima: San Marcos.

Cunha, V., \& Caixeta Filho, J. V. (2002). Gerenciamento da coleta de resíduos sólidos urbanos: estruturação e aplicação de modelo não-linear de programação por metas. Gestão \& Produção, 9(2), 143-161. http://dx.doi.org/10.1590/ S0104-530X2002000200004.

Curitiba. Prefeitura Municipal. (2013). Plano municipal de saneamento: gestão integrada de resíduos sólidos urbanos. Curitiba. 169 p. Recuperado em 1 de fevereiro de 2014, de http://multimidia.curitiba.pr.gov.br/2013/00142058.pdf

Demajorovic, J. (1995). Da política tradicional de tratamento do lixo à política de gestão de resíduos sólidos: as novas prioridades. Revista de Administração de Empresas, 35(3), 8893. http://dx.doi.org/10.1590/S0034-75901995000300010.

Dias, D. M., Martinez, C. B., Barros, R. T. V., \& Marcelo, L. (2012). Modelo para estimativa da geração de resíduos sólidos domiciliares em centros urbanos a partir de variáveis socioeconômicas conjunturais. Engenharia Sanitaria e Ambiental, 17(3), 325-332. http://dx.doi.org/10.1590/ S1413-41522012000300009.

Economopoulos, A. P. (2012). Planning tools and procedures for rational municipal solid wastes management. In A. K. Karagiannidis. Waste to energy: opportunities and challenges for developing and transition economies. London: Springer.

Ferreira, J. A., \& Anjos, L. A. (2001). Aspectos de saúde coletiva e ocupacional associados à gestão dos resíduos sólidos municipais. Cadernos de Saude Publica, 17(3), 689-696. PMid:11395805. http://dx.doi.org/10.1590/ S0102-311X2001000300023.

Finnveden, G., Johansson, J., Lind, P., \& Moberg, Ä. (2005). Life cycle assessment of energy from solid waste - part 1: general methodology and results. Journal of Cleaner Production, 13(3), 213-229. http://dx.doi.org/10.1016/j. jclepro.2004.02.023. 
Fundação Estadual do Meio Ambiente - FEAM. (2011). Panorama da destinação de Resíduos de Serviço de Saúde em Minas Gerais. Belo Horizonte. Recuperado em 23 de fevereiro de 2017, de http://www. feam.br/ minas-rss-destinacao-sustentavel

Fundação Estadual do Meio Ambiente - FEAM. (2012). Aproveitamento energético de resíduos sólidos urbanos: guia de orientação para governos municipais de Minas Gerais. Belo Horizonte.

Godet, M., Monti, R., Meunier, F., \& Roubelat, F. (2000). “A caixa de ferramentas" da prospectiva estratégica (Caderno, No. 5). Lisboa: Centro de Estudos de Prospectiva e Estratégia.

Greene, W. H. (2008). Econometric analysis (6. ed.). New Jersey: Pearson Prentice Hall.

Guerrero, L. A., Maas, G., \& Hogland, W. (2013). Solid waste management challenges for cities in developing countries. Waste Management, 33(1), 220-232. PMid:23098815. http://dx.doi.org/10.1016/j.wasman.2012.09.008.

Instituto Brasileiro de Geografia e Estatística - IBGE. (2014). Rio de Janeiro. Recuperado em março de 2014, de http:// cidades.ibge.gov.br $/$ painel/painel.php?codmun $=410690$

Instituto de Pesquisa Econômica Avançada - IPEA. (2010). Pesquisa sobre pagamento de serviços ambientais urbanos para gestão de resíduos sólidos urbanos. Brasília: DIRUR/ IPEA.

Jacobi, P. R., \& Besen, G. R. (2011). Gestão de resíduos sólidos em São Paulo: desafios da sustentabilidade. Estudos Avançados, 25(71), 135-158. http://dx.doi.org/10.1590/ S0103-40142011000100010.

Lakhan, C. (2014). Exploring the relationship between municipal promotion and education investments and recycling rate performance in Ontario, Canada. Resources, Conservation and Recycling, 92, 222-229. http://dx.doi. org/10.1016/j.resconrec.2014.07.006.

Leontitsis, A., \& Pagge, J. (2007). A simulation approach on Cronbach's alpha statistical significance. Mathematics and Computers in Simulation, 73(5), 336-340. http://dx.doi. org/10.1016/j.matcom.2006.08.001.

Lin, C. H. (2008). A model using home appliance ownership data to evaluate recycling policy performance. Resources, Conservation and Recycling, 52(11), 1322-1328. http:// dx.doi.org/10.1016/j.resconrec.2008.07.015.

Linstone, H. A., \& Turoff, M. (2002). The Delphi Method: techniques and applications. Boston: Addison-Wesley.
Lobato, K. C. D., \& Lima, J. P. (2010). Caracterização e avaliação de processos de seleção de resíduos sólidos urbanos por meio da técnica de mapeamento. Engenharia Sanitária e Ambiental, 15(4), 347-356. http://dx.doi.org/10.1590/ S1413-41522010000400007.

Lombardi, L., Carnevale, E., \& Corti, A. (2015). A review of technologies and performances of thermal treatment systems for energy recovery from waste. Waste Management, 37, 26-44. PMid:25535103. http://dx.doi.org/10.1016/j. wasman.2014.11.010.

Marchi, C. M. D. F. (2015). Novas perspectivas na gestão do saneamento: apresentação de um modelo de destinação final de resíduos sólidos urbanos. Revista Brasileira de Gestão Urbana, 7(1), 91-105. http://dx.doi.org/10.1590/21753369.007.001.A006.

Martins, G. de A. (2006). Sobre confiabilidade e validade. Revista Brasileira de Gestão de Negócios, 8(20), 1-12.

Martins, M. F., \& Cândido, G. A. (2015). Modelo de avaliação do nível de sustentabilidade urbana: proposta para as cidades brasileiras. Revista Brasileira de Gestão Urbana, 7(3), 397410. http://dx.doi.org/10.1590/2175-3369.007.003.A009.

Matsumoto, S. (2011). Waste separation at home: Are Japanese municipal curbside recycling policies efficient? Resources, Conservation and Recycling, 55(3), 325-334. http://dx.doi.org/10.1016/j.resconrec.2010.10.005.

Melo, L. A., Sautter, K. D., \& Janissek, P. R. (2009). Estudo de cenários para o gerenciamento dos resíduos sólidos urbanos de Curitiba. Engenharia Sanitária Ambiental, 14(4), 551-558.

Mesquita, J. M., Jr. (2007). Gestão integrada de resíduos sólidos. Rio de Janeiro: IBAM.

Mo, H., Wen, Z., \& Chen, J. (2009). China's recyclable resources recycling system and policy: A case study in Suzhou. Resources, Conservation and Recycling, 53(7), 409419. http://dx.doi.org/10.1016/j.resconrec.2009.03.002.

Moh, Y. C., \& Manaf, L. A. (2014). Overview of household solid waste recycling policy status and challenges in Malaysia. Resources, Conservation and Recycling, 82, 50-61. http:// dx.doi.org/10.1016/j.resconrec.2013.11.004.

Monteiro, J. H. P., Figueiredo, C. E. M., Magalhães, A. F., Melo, M. A. F., Brito, J. C. X., Almeida, T. P. F., \& Mansur, G. L. (2001). Manual de gerenciamento integrado de resíduos sólidos. Rio de Janeiro: IBAM. 
Nascimento, P., No., \& Moreira, T. A. (2010). Política Nacional de Resíduos Sólidos: reflexões a cerca do novo marco regulatório nacional. Revista Brasileira de Ciências Ambientais, 15, 10-19.

Oliveira, M. (2001). A trajetória do discurso ambiental em Curitiba (1960-2000). Revista de Sociologia e Politica, 16(16), 97-106. http://dx.doi.org/10.1590/ S0104-44782001000100007.

Othman, S. N., Zainon Noor, Z., Abba, A. H., Yusuf, R. O., \& Abu Hassan, M. A. (2013). Review on life cycle assessment of integrated solid waste management in some Asian countries. Journal of Cleaner Production, 41, 251-262. http://dx.doi.org/10.1016/j.jclepro.2012.09.043.

Paraná. Secretaria do Desenvolvimento Urbano. Coordenação da Região Metropolitana de Curitiba. (2013). Municípios da RMC. Curitiba. Recuperado em 1 julho de 2013, de http://www.comec.pr.gov.br/modules/conteudo/conteudo. php? conteudo $=89$

Pires, A., Martinho, G., \& Chang, N. (2011). Solid waste management in European countries: a review of systems analysis techniques. Journal of Environmental Management, 92(4), 1033-1050. PMid:21194829. http://dx.doi. org/10.1016/j.jenvman.2010.11.024.

Plata-Díaz, A. M., Zafra-Gómez, J. L., Pérez-López, G., \& Lópezhernández, A. M. (2014). Alternative management structures for municipal waste collection services: the influence of economic and political factors. Waste Management, 34(11), 1967-1976. PMid:25108757. http://dx.doi.org/10.1016/j. wasman.2014.07.003.

Polaz, C. N. M., \& Teixeira, B. A. N. (2009). Indicadores de sustentabilidade para a gestão municipal de resíduos sólidos urbanos: um estudo para São Carlos (SP). Engenharia Sanitária e Ambiental, 14(3), 411-420. http://dx.doi. org/10.1590/S1413-41522009000300015.

Puna, J. F. B., \& Baptista, B. dos S. (2008). A gestão integrada de resíduos sólidos urbanos - perspectiva ambiental e económico energética. Quimica Nova, 31(3), 645-654. http://dx.doi.org/10.1590/S0100-40422008000300032.

Santiago, L. S., \& Dias, S. M. F. (2012). Matriz de indicadores de sustentabilidade para a gestão de resíduos sólidos urbanos. Engenharia Sanitaria e Ambiental, 17(2), 203-212. http://dx.doi.org/10.1590/S1413-41522012000200010.

Santoyo, A. H. (2012). Bases teórico metodológicas para la valoración económica de bienes y servicios ambientales con base en técnicas de decisión multicriterio. Estudio de caso:
Parque Nacional Viñales (Tese de doutorado). Universidad de Alicante, Alicante.

Saphores, J. M., \& Nixon, H. (2014). How effective are current household recycling policies? Results from a national survey of U.S. households. Resources, Conservation and Recycling, 92, 1-10. http://dx.doi.org/10.1016/j. resconrec.2014.08.010.

Schalch, V., Leite, W. C. A., Fernandes, J. L. Jr., \& Castro, M. C. A. A. (2002). Gestão e gerenciamento de resíduos sólidos. São Carlos: USP.

Silva, C. L. (2016). Avaliação da política municipal da gestão integrada de resíduos sólidos urbanos de Curitiba. Curitiba: Ed. do Autor. Relatório Técnico. Recuperado em julho de 2016, de https://observatoriopnrs.files.wordpress. com/2016/06/relatorio-pmgirs-curitiba-junho-2016.pdf

Silva, C. L., \& Biernaski, I. (2015). Políticas públicas de resíduos sólidos urbanos: uma analise de três metrópoles brasileiras. Revista Direito Empresarial, 12, 11-33.

Silva, C. L., Fugii, G. M., Bassi, N. S. S., \& Santoyo, A. H. (2015). 0 que é relevante para planejar e gerir residuos solidos? Uma proposta de definição de variáveis para a formulação e avaliação de políticas públicas. Biblio $3 w$ : Revista Bibliográfica de Geografía y Ciencias Sociales, 20(1114), 1-25.

Sistema Nacional de Informações Sobre a Gestão de Resíduos Sólidos - SNIS. (2008). Diagnóstico do manejo de Resíduos Sólidos Urbanos - 2008. Recuperado em 23 fevereiro de 2016, de http://www.snis.gov.br/diagnostico-residuos-solidos/ diagnostico-rs-2008

Sistema Nacional de Informações Sobre a Gestão de Resíduos Sólidos - SNIS. (2009). Diagnóstico do manejo de Resíduos Sólidos Urbanos - 2009. Recuperado em 23 fevereiro de 2016, de http://www.snis.gov.br/diagnostico-residuos-solidos/ diagnostico-rs-2009

Sistema Nacional de Informações Sobre a Gestão de Resíduos Sólidos - SNIS. (2010). Consulta de indicadores de resíduos sólidos urbanos. Brasília. Recuperado em 1 junho de 2013, de http://www.sinir.gov.br/web/guest/ consulta-de-indicadores

Sistema Nacional de Informações Sobre a Gestão de Resíduos Sólidos - SNIS. (2011). Diagnóstico do manejo de Resíduos Sólidos Urbanos - 2011. Recuperado em 23 fevereiro de 2016, de http://www.snis.gov.br/diagnostico-residuos-solidos/ diagnostico-rs-2011 
Sistema Nacional de Informações Sobre a Gestão de Resíduos Sólidos - SNIS. (2012). Diagnóstico do manejo de Resíduos Sólidos Urbanos - 2012. Recuperado em 23 fevereiro de 2016, de http://www.snis.gov.br/diagnostico-residuos-solidos/ diagnostico-rs-2012

Sistema Nacional de Informações Sobre a Gestão de Resíduos Sólidos - SNIS. (2013). Diagnóstico do manejo de Resíduos Sólidos Urbanos - 2013. Recuperado em 23 fevereiro de 2016, de http://www.snis.gov.br/diagnostico-residuos-solidos/ diagnostico-rs-2013

Sistema Nacional de Informações sobre Saneamento SNIS. (2014). Brasília. Recuperado em 1 junho de 2013, de http://www.snis.gov.br/diagnostico-residuos-solidos

Soltani, A., Hewage, K., Reza, B., \& Sadiq, R. (2015). Multiple stakeholders in multi-criteria decision-making in the context of Municipal Solid Waste Management: A review. Waste Management, 35(1), 318-328. PMid:25301545. http:// dx.doi.org/10.1016/j.wasman.2014.09.010.

Suzuki, J. A. N., \& Gomes, J. (2009). Consórcios intermunicipais para a destinação de RSU em aterros regionais: estudo prospectivo para os municípios no Estado do Paraná. Engenharia Sanitária e Ambiental, 14(2), 155-158. http:// dx.doi.org/10.1590/S1413-41522009000200002.

Tanigaki, N., Ishida, Y., \& Osada, M. (2015). A case-study of landfill minimization and material recovery via waste co-gasification in a new waste management scheme. Waste Management, 37, 137-146. PMid:25182227. http://dx.doi. org/10.1016/j.wasman.2014.07.024.

Tchobanoglous, G., \& Kreith, F. (2002). Handbook of solid waste managment (2. ed.). New York: McGraw-Hill.

Thomas, B., \& McDougall, F. (2005). International expert group on life cycle assessment for integrated waste management. Journal of Cleaner Production, 13(3), 321326. http://dx.doi.org/10.1016/j.jclepro.2004.02.021.

United States Environmental Protection Agency - US EPA. (2002). Solid waste management: a local challenge with global impacts (p. 1-22). Washington.

Wan, C., Shen, G. Q., \& Yu, A. (2014). The role of perceived effectiveness of policy measures in predicting recycling behaviour in Hong Kong. Resources, Conservation and Recycling, 83, 141-151. http://dx.doi.org/10.1016/j. resconrec.2013.12.009.

Weiss, M. C., Bernardes, R. C., \& Consoni, F. L. (2015). Cidades inteligentes como novas práticas para o gerenciamento dos serviços e infraestruturas urbanos: a experiência da cidade de Porto Alegre. Revista Brasileira de Gestão Urbana, 7(3), 310-324. http://dx.doi.org/10.1590/21753369.007.003.A001.

Wilson, D., Whiteman, A., \& Tormin, A. (2001). Strategic planning guide for municipal solid waste management. Washington: World Bank.

Zanta, V. M., \& Ferreira, C. F. A. (2003). Gerenciamento integrado de resíduos sólidos. In A. B. Castilhos (Ed.), Resíduos sólidos urbanos: aterro sustentável para municípios de pequeno porte. Rio de Janeiro: ABES-RiMa.

Zurbrügg, C. (2003). Urban solid waste management in low-income countries of Asia how to cope with the garbage crisis. In Scientific Committee on Problems of the Environment (SCOPE) Urban Solid Waste Management Review Session (p. 1-13), Durban, South Africa.

Recebido: Mar. 14, 2016

Aprovado: Out. 10, 2016 